\title{
Effects of Indigenous Epistemology on Indigenous Secondary Retention Rates
}

\author{
Tiffany Prete \\ University of Alberta \\ tbevans@ualberta.ca
}

\begin{abstract}
This article presents the findings of a qualitative study that examines how Indigenous epistemology ${ }^{1}$ affects secondary Indigenous students' retention rates within public schools. The purpose of this study was to focus on Indigenous epistemology that is present in Indigenous culture and language courses to determine whether Indigenous students who engage in this curriculum have higher success ${ }^{2}$ rates than those of Indigenous students who do not participate in this particular curriculum. As a Blackfoot scholar, I used a Blackfoot theoretical framework grounded in an Indigenous research methodology. Eight Blood Tribe members were interviewed: four participants (three graduates and one non-graduate) who attended a high school with Indigenous epistemology courses (offered Blackfoot language classes and Aboriginal Studies) and four participants (three graduates and one non-graduate) who attended a high school that did not offer Indigenous epistemology courses (did not offer Blackfoot language classes and Aboriginal Studies). The findings show that not only does the epistemology in the school play a role in Indigenous students' success in public education, but the epistemology also accompanies and influences the participants throughout their adult lives by shaping their identities and affecting how they function as adults.
\end{abstract}

\section{Introduction}

"As Natives", [our culture and language] is all we have left in today's modern world; and if we cannot teach this to our children, then we would be a lost Tribe" (Research participant Tony, Prete, 2011, pg. 116).

Numerous sources have indicated that for the past several decades, the Indigenous People of Canada have the highest early school departure rates ${ }^{4}$ than any other ethnicity in Canada (Royal Commission on Aboriginal Peoples, 1996; Indigenous Services Canada, 2003; Human Resources and Skills Development Canada, 2009; Mendelson, 2006; Assembly of First Nations, 2009; Alberta School Boards Association, 2011). Since the creation of Canada, the education of

\footnotetext{
${ }^{1}$ Epistemology "provides cultures with a philosophical and theoretical framework of assumptions for seeking knowledge as well as processes that define truth" (Bastien, 2004, p. 98).

${ }^{2}$ For the purposes of this paper, success is related to the participants' ability to obtain a high school diploma, create a positive cultural identity and find meaningful employment outside of high school.

${ }^{3}$ Please note that the preferred identification of the research participants is Native American, as the Blackfoot Confederacy resides in both Canada and the United States.

${ }^{4}$ I take the position, that the manner in which Eurocentric Western school systems educate Canadian Indigenous Peoples is a systemic issue which has led to the low achievement of Indigenous Peoples in public schools. Therefore, I choose to use the terminology "early departure rate" rather than "dropout rates" as factors exist which are beyond the control of Indigenous Peoples that have led to their low graduation rates.

Journal of Contemporary Issues in Education, 2018, 13(1), pp. 23-36

ISSN 1718-4770 (C) 2018 University of Alberta/Centre for Global Citizenship Education and Research 
Indigenous People has been a federal responsibility as stated in the British North American Act (1867) and the original Indian Act (1876). A major revision in the Indian Act (1985) resulted in a government agreement to hold provincial and territorial schools accountable for the education of Indigenous students; and consequently they are now accountable for their respective Indigenous early school departure rates.

Alberta Education rose to the occasion by creating its first policy framework titled the Native Education Project (NEP) which ran from 1987-2000 (Alberta Education, 1987). NEP created Indigenous language courses and envisioned a curriculum that would depict a positive view of Aboriginal Peoples and encourage Native Peoples to become part of their children's education (Alberta Education, 1987; Scheffel, 2000). After less than positive reviews during its first progress report (Alberta Education, 2000), Alberta Education terminated the project in 2000. The NEP was never made mandatory and its implementation was only encouraged, especially in schools that had a high population of Indigenous students.

In the fall of 2002, Alberta Education came out with the First Nations, Metis and Inuit policy framework (FNMI), by making revisions from the NEP progress report. This time the policy framework was mandatory in all schools across Alberta (Alberta Education, 2002), which built upon the objectives of the NEP frame work. Additionally Alberta Education created an Aboriginal Studies coursework; however, the Indigenous language and Aboriginal Studies were optional courses and were not offered in every school in Alberta.

During my graduate studies, I became increasingly aware that the public schools that educated many of the Indigenous students from my Reserve (Blood Tribe), did not or were no longer offering Indigenous language programs or the Aboriginal Studies coursework. This news was troublesome to me, as the omission of these classes indicate that our Blackfoot language and our culture are not important to the Eurocentric Western based education system. I wanted to engage in a research study that would determine whether or not these classes have value to Indigenous students and should therefore be offered in schools. I also became curious about Indigenous students' experiences in schools that did and did not offer such classes; as well, how having their Indigenous epistemology a part of the school affected their ability to graduate from high school.

\section{Purpose and Significance of the Research}

It was my intent to further examine the relationship between Indigenous secondary retention rates and Indigenous epistemology. For the purpose of this study I focused on Blackfoot culture and language courses, as these classes will include Blackfoot epistemology ${ }^{5}$. I wanted to determine whether Indigenous students who engage in said curriculum have higher success rates than those of Indigenous who do not participate in this particular curriculum by examining three areas of the participants' high school experience.

\footnotetext{
${ }^{5}$ Blackfoot epistemology is "dependent upon relationships, which create and generate knowledge (Bastien, 2004, p. 77).

Journal of Contemporary Issues in Education, 2018, 13(1), pp. 23-36

ISSN 1718-4770 (C) 2018 University of Alberta/Centre for Global Citizenship Education and Research

http://ejournals.library.ualberta.ca/index.php/JCIE
} 
First, I examined the effect of the epistemology present in the school on the participants' school experiences. These experiences determined whether the participants were motivated or not to graduate from high school. Second, I examined the effect of the epistemology present in the school on the participants' identity formation; a positive cultural identity formation may have helped them to graduate from high school. Last, I examined the effect of the epistemology present in the school on the participants' lives after high school. I hoped that this study would shine some light on the question of whether Indigenous students succeed best in Indigenous or Eurocentric Western epistemology based learning.

The literature I reviewed for this study identified many factors that either contributed to or decreased Indigenous early departure rates; however, very few studies have directly addressed the extent to which Indigenous epistemology or its lack in the curriculum affect dropout rates. I therefore hoped that this work would be a significant contribution to scholarly research and to Indigenous education in public schools. Determining a suitable epistemology might be critical to the success of Indigenous education.

\section{Literature Review}

Copious research studies have been conducted into why some secondary students graduate from high school while others do not, which aid to inform this study. The focus of the research has been on primary factors (directly affecting the individual) and secondary factors (indirectly affecting the individual) which inhibits the students' ability to graduate from high school. Primary factors consist of substance abuse (Aloise-Young, Cruikshank, \& Chavez, 2002; Drapela, 2006; Renna, 2008), low self-esteem (Awad, 2007; Hale, 2001; Lockett \& Harrell, 2003), lack of self-identity (Awad, 2007; Locket \& Harrell, 2003; Wigfield \& Wagner, 2005), peer pressure (Ladd \& Troop-Gordon, 2003; Véronneau, Vitaro, Pedersen, \& Tremblay, 2008; Wentzel, 2003), and teenage pregnancy (Rothenberg \& Weissman, 2002; Stewart, 2003; Weisfeld \& Woodward, 2004).

Secondary factors consist of two areas that can inhibit students' ability to graduate. First, the impact of family background on the likelihood that students will drop out of high school; specifically, socioeconomic status (Miller, 1995; South, Baumer, \& Lutz, 2003), educational attainment (Silver, Mallett, Greene, \& Simard, 2002; van der Woerd \& Cox, 2003; Ward, 1995) and educational attitudes of the family (Amstutz \& Sheared, 2000; Anguiano, 2004; Davis-Kean, 2005). The second area focus is on the effect of the school environment on student achievement; specifically, racism, prejudice, and discrimination (Véronneau et al., 2008; Sockbeson, 2011; St. Denis \& Hampton, 2002), feelings of belongingness (Christenson, Sinclair, Lehr, \& Hurley, 2000; Makokis, 2000; Silver, Mallett, Greene, \& Simard, 2002), individual values and goals (Silver et al., 2002; E. L. Steinhauer, 2007; P. J. Steinhauer, 1999), and the desire to achieve academically (Makokis, 2000; E. L. Steinhauer, 2007; N. R. Steinhauer, 1999).

The primary and secondary factors listed above can influence any student regardless of ethnicity. Missing from this discourse are research studies that have been conducted to examine specifically why Indigenous students have high early school departure rates. A Eurocentric lens has largely been used to examine this problem; which has resulted in Indigenous People being

Journal of Contemporary Issues in Education, 2018, 13(1), pp. 23-36 
viewed as the problem. The most notable theories using a Eurocentric lens are the 1960s cultural discontinuity theory (CDT) (Erickson, 1987; Manning \& Baruth, 2009; Ogbu, 1982) followed by the culturally appropriate curriculum theory (CACT) (Harris, 1990; McCarthy, 1994; Spring, 1998).

The cultural discontinuity theory became very attractive to educators because it did not place blame on either the student or the school, but rather placed blame on cultural misunderstandings (Erickson, 1987). While the culturally appropriate curriculum theory believed that in order for ethnic minority students to be successful, the curriculum needed to include culturally appropriate curriculum (Agbo, 2001). Neither of these theories examined what is wrong with the education system and why it is failing to meet the needs of its ethnically diverse students. Recent research studies have raised a number of concerns over CACT. First, is CACT being reduced to cultural components in the curriculum which can lead to: a superficial awareness of the Peoples (LadsonBillings \& Tate, 2006), exclusion of learning about the Peoples oppression (Kaomea, 2003), and stereotyping (St. Denis, 2010). Additionally, CACT does not address the following for Indigenous Peoples: injustices that are experienced, victimization for 'losing' their culture, racial inequality from a systemic historical context, or racism (St. Denis, 2007).

The review of the literature clearly outlines the dangers of using cultural components in the classroom. What has not been addressed is, what are the effects when Indigenous epistemology is the basis of coursework designed to teach about Indigenous language and culture? This research study attempts to answer this question by focusing on what effect Blackfoot epistemology has on Blackfoot students in public schools.

\section{Research Question}

The research question that guided this study was, "How does engaging with an Indigenous epistemology affect secondary student Indigenous retention rates within public educational systems?" The two sub-questions related to the original research question are as follows:

1. How does the epistemology in the school shape identity construction?

2. How does the epistemology in the school affect life after high school?

\section{Method}

As a Blackfoot scholar, my research used a Blackfoot theoretical framework grounded in Blackfoot epistemology as outlined in Blackfoot scholar Betty Bastien's (2004) work. Additionally, I employed an Indigenous research methodology as informed by Martin (2002) and Weber-Pillwax's (2001) principles of Indigenous research, and Wilson's (2008) Indigenous research paradigm. Underpinning this methodology is the notion of choosing methods which will uphold and honour the People who are a part of the study. It incorporates the ways of knowing and ways of being of the People involved in the study; thus semi-structured individual interviews and storytelling methods were used. I wanted to engage in research that would be of service to my People (Meyer, 2003), thus this research takes place on the Blood Reserve. As well, the consent of the Chief and Council of the Blood Reserve was granted before I began this research

Journal of Contemporary Issues in Education, 2018, 13(1), pp. 23-36 
study. Data analysis consisted of thematic analysis, in which I created themes and categories to "adequately encompass and summarize the data" (Gall, Gall, \& Borg, 2003, p. 453).

\section{Participants}

Participants were eight young adults from the Blood Tribe (part of the Blackfoot Confederacy). One group of four participants (Ben, Tony, Sonya and Anna) had attended a high school with Blackfoot epistemology present (offered Blackfoot language classes and Aboriginal Studies) and had taken one of the two Blackfoot epistemology courses; and a second group of four participants (Tia, Thomas, Dwight and Brian) had attended a non-Blackfoot epistemology high school (did not offer Blackfoot language classes and Aboriginal Studies). Participants were a mixture of high school graduates and non-graduates.

\section{Findings}

\section{Participants who attended a high school with Blackfoot epistemology}

This section outlines Ben, Tony, Sonya and Anna's school experience, identity construction, and post-high school experience.

\section{School Experience}

The participants voiced three aspects of their school experience that helped motivate them to stay in school. First, all of the participants agreed that their Blackfoot language and culture classes were something that they looked forward to, and helped motivate them to continue attending school. Second, individuals in the participants' lives helped motivate them to keep going. Anna named a teacher, school counsellor and school principal who were instrumental in helping her finish high school after her early school departure. Speaking about her school counsellor, Anna stated, "he was always asking what he could do" (Prete, 2011, pg. 109). Third, Ben, Tony and Sonya found the social aspect of school (atmosphere, dances, and school functions), motivating to continue attending school. Tony and Sonya shared what deterred them from graduating on time. Both Tony and Anna skipped school, while Anna became pregnant in her $12^{\text {th }}$ school year.

\section{Identity Construction}

All of the participants voiced that it was not until they started attending school that they became cognizant of their ethnicity. In their elementary years, the participants became aware of the negative perceptions held in the town and school where they were educated regarding Indigenous Peoples. These misconceptions often lead to cultural tensions within the school which negatively impacted their cultural identity and affected their high school experiences. All of the participants felt that their Blackfoot language and culture classes helped them to develop positive cultural identities. Sonya shared, "Regular classes helped with my organization, study skills, and achieving in that way. Cultural classes have helped my identity" (Prete, 2011, p. 116).

\section{Post-High School Experience}

Each of the participants graduated. Ben and Sonya graduated on time, Tony graduated after five continuous years, and Anna left school to return two years later. Currently Ben, Sonya and Anna 
hold a degree or certificate. In the future, all of the participants would like to pursue more postsecondary education.

\section{Participants who did not attend a high school with Blackfoot epistemology}

This section outlines Tia, Thomas, Dwight and Brian's school experience, identity construction, and the post-high school experience.

\section{School Experience}

The participants voiced three aspects of their school experience that helped motivate them to stay in school. First is the school's sports teams. Tia, Thomas, Dwight were athletic and played on more than one sports team. Second, each participant had a favourite class that would draw them to school. Third, Tia, Thomas and Dwight enjoyed their school atmosphere (friendly environment, helpful school staff, and school activities). However, all of the participants remarked that missing from their high school experience was Blackfoot language and culture classes. Tia felt in particular the importance of non-Indigenous People learning about Indigenous People. She shared "I think it would be good for them to be aware of the cultural differences. If they can understand why maybe some of the problems go on in our lives, perhaps it helps them to better understand us more" (Prete, 2011, pg. 141).

The participants shared four discouraging factors that affected their willingness to attend school. First, Dwight encountered unsupportive staff members towards Indigenous students. Second, Brian faced school bulling that eventually lead to his early school departure. Third, Tia and Brian felt isolated in their schools as they were the only Indigenous students attending. Fourth, skipping was a factor that played a role in Thomas and Brain's ability to graduate on time. Fifth, Dwight and Brain also faced racism in the schools that they attended.

\section{Identity Construction}

In the absence of Blackfoot language and culture classes, the participants received reinforcement about their cultural identities in positive and negative ways. The school's Native Honour Night ${ }^{6}$ positively affected Thomas's cultural identity. Thomas and Dwight felt their schools Native Awareness $\mathrm{Week}^{7}$ positively affected their cultural identity. However, the function was not mandatory and many non-Indigenous students decided to not attend; this negatively affected Dwight and Thomas. Dwight stated, "it was a time for students to like take off from school and do something else" (Prete, 2011,pg. 145). Dwight encountered racism, which negatively affected his cultural identity construction. Brian and Tia were the only Indigenous students in their school, which negatively affected their cultural identity. Tia was eventually able to overcome these feelings, while Brian could not and departed from school early.

\section{Post-High School Experience}

Tia and Dwight graduated on time, Thomas graduated after four years, and Brian departed from school early. Currently, Tia holds a degree, Dwight is actively pursuing a degree, Thomas

\footnotetext{
${ }^{6}$ Native Honour Night is how the school has named this function.

${ }^{7}$ Native Awareness Week is how the school has named this function.

Journal of Contemporary Issues in Education, 2018, 13(1), pp. 23-36

ISSN 1718-4770 (C) 2018 University of Alberta/Centre for Global Citizenship Education and Research

http://ejournals.library.ualberta.ca/index.php/JCIE
} 
departed from college early, and Brian has entered college to complete his high school degree. In the future, all of the participants are contemplating pursuing additional post-secondary education.

\section{Research Question 1}

"How does engaging with an Indigenous epistemology affect secondary student Indigenous retention rates within public educational systems?" I designed the research question to assess whether the epistemology in the school affects secondary retention rates.

\section{High school with Blackfoot epistemology}

The school with Blackfoot epistemology included a co-existing Indigenous and non-Indigenous epistemology, whereas the high school without Blackfoot epistemology followed only a nonIndigenous epistemology. Students who attended a school with Blackfoot epistemology had a choice of one or the other epistemology. However, misconceptions about each cultural group (Indigenous and non-Indigenous) were very evident in the school, which resulted in segregation between them. Ben and Sonya chose to ignore the misconceptions about their People and chose an Indigenous epistemology; consequently, Ben and Sonya took Blackfoot each year in high school and graduated after three years. On the other hand, Anna believed the negative misconceptions about her People and chose a non-Indigenous epistemology; she departed from high school early. However, two years later she returned to high school and engaged in an Indigenous epistemology, and graduated at the end of that year. Tony also chose an Indigenous epistemology, which he was fortunate to find in all three high schools that he attended. This might be the reason that Tony did not drop out of school, but persevered for five years before he received his high school diploma.

\section{High school without a Blackfoot epistemology}

On the other hand, Thomas, Brian, and Tia did not have the option of choosing an Indigenous epistemology because no Indigenous courses were available to them; their only option was a non-Indigenous epistemology. Tia graduated within three years, Thomas within four years, and Brian has not yet graduated. Tia revealed that she grew up in a home that taught a Blackfoot epistemology, which might be the reason that she was successful and able to graduate from high school within three years. Tia also took Blackfoot language classes in junior high. Thomas had received some Blackfoot teachings in his home, but not necessarily about Blackfoot epistemology; this may be why it took Thomas four years to graduate. Brian did not have any contact with his People and did not have any opportunities to learn about his People's epistemology; this may be why he did not graduate. When Brian returned to his home Reserve and began to learn about himself and his People, he was able to return to school and begin to finish his education. Conversely, Dwight attended two schools with an Indigenous epistemology and two that lacked an Indigenous epistemology. He took Blackfoot 10 in his first year of high school, but because he was fluent in the Blackfoot language, he chose not to continue with additional Blackfoot classes. Dwight graduated after three years. His success may be attributed to his engagement in one class that followed an Indigenous epistemology or to his having grown up in a home that also had an Indigenous epistemology. 
These results tentatively indicate that an Indigenous epistemology plays a role in Indigenous students' success in public education; more research is needed to conclude that a definite relationship exists.

\section{Sub-Question 1}

The first sub-question is, "How does the epistemology in the school shape identity construction?" The participants' school experiences heavily influenced their identity formation, and the first sub-question sought to determine whether the epistemology in their schools also affected their identity formation.

\section{High school with Blackfoot epistemology}

The misconceptions perpetuated in the school with a Blackfoot epistemology led the participants to examine their identity. Ben, Sonya, and Tony benefited from the negative experiences by seeking other perceptions and answers to their questions about Indigenous Peoples. None of these three participants accepted the misconceptions as truth, which led to a positive cultural identity. Conversely, Anna believed the misconceptions; thus, she did not want to be associated with her Indigenous People. As discussed above, the school with a Blackfoot epistemology had two epistemologies present, and the participants had a choice; however, the misconceptions also played a role in which epistemology they chose. Thus, the epistemology that they chose greatly affected how they constructed their identity.

\section{High school without a Blackfoot epistemology}

The school without a Blackfoot epistemology had only one epistemology that centered on sports for three of the participants; hence, they developed their identities as athletes rather than their cultural identity as Indigenous persons. Brian did not develop an identity based on the epistemology of his People or the school he attended. In his school Brian was treated with low expectations, and he lived up to these low expectations. Therefore Brian departed from high school early. The epistemologies in the school greatly affect identity formation in that students can choose one epistemology over another or follow the only epistemology.

\section{Sub-Question 2}

The second sub-question is, "How does the epistemology in the school affect life after high school?" I designed the second sub-question to determine how the epistemologies in the participants' schools affected their lives after high school.

\section{High school with Blackfoot epistemology}

Those who attended a school with a Blackfoot epistemology were exposed to an Indigenous epistemology and all graduated from high school; Ben, Sonya and Anna went on to obtain a university degree or college certificate. Tony's goal is to attend college in the near future. The participants also have short-term and long-term goals; for many of them, their long-term goal is to pursue further education.

\section{High school without a Blackfoot epistemology}


However, the participants who attended a school without a Blackfoot epistemology have had mixed outcomes. Tia obtained a bachelor's degree, Dwight is currently working on his undergraduate degree, Thomas departed from his degree program early, and Brian is working on his high school diploma. Tia and Dwight expressed interest in pursuing more postsecondary education, and Brian and Thomas are contemplating returning to postsecondary education. Tia, Thomas and Dwight also have more short-term than long-term goals. Brian is the only participant with dreams for the future, but he was unsure which one he wanted to pursue; however, it may be that his dreams have helped him to succeed this far in life.

Therefore, the Indigenous epistemology appears to have had a positive effect on the Indigenous participants' lives and well-being compared to a non-Indigenous epistemology. However, more research is required to determine more concretely whether the epistemology in the school affects students' lives after high school. It is very clear from this research that the pronounced epistemology in the schools has shaped the identities of the participants, influenced them in their adult lives, and affected how they function as adults.

\section{Recommendations}

Based on the results of the study, I have formulated a number of future considerations for educational policy and future research. First, I strongly suggest that Indigenous coursework be offered in school, at the grade 10,11 and 12 levels, for their Indigenous students' academic success. The research results indicated that Blackfoot language and culture classes positively influenced the participants' experiences in high school. Having Blackfoot language and culture classes in the school also helped the participants to succeed academically by motivating them to regularly attend their schools that offered Indigenous coursework, as well, the participants were able to develop a stronger understanding of their Indigenous identities which helped them to persevere through school and graduate despite challenges they encountered in their high school. Not all Indigenous students have access to language, cultural, and historical teachings in their homes; therefore, public schools is one alternative that can help Indigenous students understand their heritage. Sonya commented:

I think that [Blackfoot culture and language] also are very beneficial. I think it is good to offer them in schools, especially for people with culture, and in my case, being Native. You don't always necessarily get that type of learning at home. So it offers another outlet for you to learn more about your culture. (Prete, 2011, pg. 111)

I also recommend that Indigenous language and culture classes be offered in all high schools that serve First Nations Reserves and that school administrators consider onsite classes or satellite classrooms for their school districts. Thus, if classroom attendance is an issue, school districts should consider making satellite classrooms available to students in the district who are interested in participating.

Second, I strongly suggest that an Indigenous culture and history class be developed and implemented in all Alberta public high schools. All public secondary students must complete this course at a grade 10 level in order to graduate from high school. This course should be designed

Journal of Contemporary Issues in Education, 2018, 13(1), pp. 23-36 
to stress the students own moral deliberations on the Indigenous Peoples experience through the examination of Indigenous People's history and the effects of colonialism. This course should begin by reviewing the Indigenous Peoples of the Americas before contact with European settlers. Next, the course should proceed to examine colonialism and its effects on America's Indigenous Peoples and the creation of modern day America through the use of interrogating primary documents (diaries, speeches, letters, and government documents) and Indigenous Peoples experiences until present time. This course may have the potential to decrease misconceptions that can arise about Indigenous People today.

Third, I strongly suggest that each school facilitate the growth of their Indigenous students' identities. It might include an Indigenous students organization that would include a cohort group to discuss the challenges that students might be facing, such as feelings of isolation in a predominantly non-Indigenous school; and the school might also offer Indigenous students an opportunity to learn more about their culture and history by inviting guest lecturers or allowing them to go on field trips to learn more about their backgrounds. Research participant Sonya suggested a number of ways that she felt that schools could improve:

I think perhaps including cultural activities for Native students to attend, and even non-Natives. Dance classes could be offered; more resources such as tutoring for Native American students; afterschool programs even. I think even having a better-structured Native department. I think more needs to be implemented than just culture classes. (Prete, 2011, p. 159)

\section{Limitations}

Throughout the study a number of implications for future studies on the effects of epistemology on secondary retention rates were evident. First, the size of the respondent group was relatively small: four participants in a high school with Blackfoot epistemology and four in a school without Blackfoot epistemology; this size might not have been large enough to apply their experiences to those of other Blood Indigenous students within the public education system. This may be especially true for students who departed from high school early, with only two of the participants in the study with early departures. Therefore, this study could benefit from a larger respondent group of six to eight more participants in each category to reduce respondent bias and increase the validity of the findings.

Second, the study did not account for the effect of growing up in more traditional homes on students' identities and educational experiences. The purpose of the study was to examine the participants' experiences in either a school that did or did not offer Blackfoot epistemology with a focus on only school-dependent factors. However, it is difficult to explore only the schooldependent factors when students are very much influenced by their home conditions. The findings indicate that the students who had already engaged in their People's epistemology in the home had positive experiences at school; thus Indigenous students who engage in Indigenous epistemology in their schools should also have positive experiences at their schools.

Journal of Contemporary Issues in Education, 2018, 13(1), pp. 23-36 


\section{References}

Agbo, S. A. (2001). Enhancing success in American Indian students: Participatory research at Akwanese as part of the development of a culturally relevant curriculum. Journal of American Indian Educator, 40(1), 31-55.

Alberta Education. (1987). Policy statement on Native education in Alberta.

Alberta Education (2000). Native education policy review.

Alberta Education (2002). First Nations, Métis, and Inuit education policy framework.

Alberta School Boards Association. (2011). Ensuring First Nations, Metis and Inuit student success. Leadership through governance. Available at http://www.asba.ab.ca/wpcontent/uploads/2014/07/Inuit_success_report.pdf

Aloise-Young, P. A., Cruikshank, C., \& Chavez, E. L. (2002). Cigarette smoking and perceived health in school dropouts: A comparison of Mexican American and non-Hispanic white adolescents. Journal of Pediatric Psychology, 6, 497-507. https://dx.doi.org/10.1093/jpepsy/27.6.497

Amstutz, D. D., \& Sheared, V. (2000). The crisis in adult basic education. Education and Urban Society, 32(2), 155-166. https://dx.doi.org/10.1177/0013124500322001

Anguiano, R. P. V. (2004). Families and schools: The effect of parental involvement on high school completion. Journal of Family Issues, 25(1), 61-85. https://dx.doi.org/10.1177/0192513X03256805

Assembly of First Nations. (2009). National Chief Phil Fontaine speaking notes for Council of the Ministers of Education, Canada (CMEC): Summit on Aboriginal education:

Strengthening Aboriginal success, moving toward Learn Canada 2020. Retrieved from https://www.cmec.ca/Publications/Lists/Publications/Attachments/221/aboriginal_summi t_report.pdf

Awad, G. J. (2007). The role of racial identity, academic self-concept, and self-esteem in the prediction of academic outcomes for African American students. Journal of Black Psychology, 33(2), 188-207. https://dx.doi.org/10.1177/0095798407299513

Bastien, B. (2004). Blackfoot ways of knowing: The worldview of the Siksikaitsitapi. Calgary, AB: University of Calgary Press.

British North America Act. (1867). Retrieved from http://www.solon.org/Constitutions/Canada /English/ca_1867.html

Christenson, S. L., Sinclair, M. F., Lehr, C. A., \& Hurley, C. M. (2000). Promoting successful school completion. In K. M. Minke \& G. C. Bears (Eds.), Preventing school problems: Promoting school success (pp. 221-257). Bethesda, MD: National Association of School Psychologists.

Davis-Kean, P. E. (2005). The influence of parent education and family income on child achievement: The indirect role of parental expectations and the home environment. Journal of Family Psychology, 19(2), 294-304. https://dx.doi.org/10.1037/08933200.19.2.294

Drapela, L. A. (2006). Investigating the effects of family, peer, and school domains on postdropout drug use. Youth and Society, 37(3), 316-347.

https://dx.doi.org/10.1177/0044118X05278264

Journal of Contemporary Issues in Education, 2018, 13(1), pp. 23-36 
Erickson, F. (1987). Transformation and school success: The politics and culture of educational achievement. Anthropology \& Education Quarterly, 18(4), 335-356. https://dx.doi.org/10.1525/aeq.1987.18.4.04x0023w

Gall, M. D., Gall, J. P., \& Borg, W. R. (2003). Educational research: An introduction ( $7^{\text {th }}$ ed.). Boston, MA: Allyn and Bacon.

Hale, J. (2001). Learning while Black: Creating educational excellence for African American children. Baltimore, MD: Johns Hopkins University Press.

Harris, S. (1990). Two-way Aboriginal education: Education and cultural survival. Canberra: Aboriginal Studies Press.

Human Resources and Skills Development Canada. (2009). Indicators of well being in Canada: Learning, educational attainment. Available at https:/uwaterloo.ca/canadian-indexwellbeing/sites/ca.canadian-index-wellbeing/files/uploads/files/EducationFull_Report.sflb_.pdf

Indian Act (1876). Available at http://www.ainc-inac.gc.ca/ai/arp/ls/pubs/1876c18/1876c18eng.pdf

Indian Act (1985). Available at http://laws.justice.gc.ca/eng/I-5/page-18.html\#anchorboga:s_114

Indigenous Services Canada. (2003, December). Education Programs. Report.

Kaomea, I. (2003). Reading erasures and making the familiar strange: Defamiliarizing methods for research in formerly colonized and historically oppressed communities. Educational Researcher, 32(2), 14-25. https://dx.doi.org/10.3102/0013189X032002014

Ladd, G. W., \& Troop-Gordon, W. (2003). The role of chronic peer difficulties in the development of children's psychological adjustment problems. Child Development, 74(5), 1344-1367. https://dx.doi.org/10.1111/1467-8624.00611

Ladson-Billings, G., \& Tate, W. F. (2006). Toward a critical race theory of education. In H. Lauder, P. Brown, J. Dillabough, \& A. H. Halsey (Eds.), Education, globalization \& social change (pp. 570-585). Oxford, New York: Oxford University Press.

Lockett, C. T., \& Harrell, J. P. (2003). Racial identity, self-esteem, and academic achievement: Too much interpretation, too little supporting data. Journal of Black Psychology, 29(3), 325-336. https://dx.doi.org/10.1177/0095798403254216

Makokis, P. (2000). An insider's perspective: The dropout challenge for Canada's First Nations. Unpublished doctoral dissertation, University of San Diego, San Diego, CA.

Manning, M. L., \& Baruth, L. G. (2009). Multicultural education of children and adolescents (5th ed.). Boston: Pearson.

Martin, K. (2002). Ways of knowing, ways of being, and ways of doing: Developing a theoretical framework and methods for Indigenous re-search and Indigenist research. Unpublished manuscript.

McCarthy, C. (1994). Multicultural discourses and curriculum reform: A critical perspective. Educational Theory, 44(1), 81-98.

Mendelson, M. (2006). Aboriginal Peoples and postsecondary education in Canada. Ottawa: Caledon Institute of Social Policy.

Meyer, M. (2003). Ho'oulu: Our time of becoming Hawaiian epistemology and early writings. Honolulu, HI: Ai Pohaku Press.

Miller, L. S. (1995). An American imperative: Accelerating minority educational advancement: Review. Yale University Press. 
Ogbu, J. U. (1982). Cultural discontinuities and schooling. Anthropology and Education Quarterly, 13(4), 290-307. https://dx.doi.org/10.1525/aeq.1982.13.4.05x1505w

Prete, T. D. (2011). Indigenous student perspectives on high school retention: Education experiences grounded in indigenous epistemology and western epistemology. Master's thesis, University of Alberta, Edmonton, AB, Canada.

Renna, F. (2008). Teens' alcohol consumption and schooling. Economics of Education Review, 27(1), 69-78. https://dx.doi.org/10.1016/j.econedurev.2006.05.002

Rothenberg, A., \& Weissman, A. (2002). The development of programs for pregnant and parenting teens. School Work in Health Care, 35(1), 65-83. https://dx.doi.org/10.1300/J010v35n03_05

Royal Commission on Aboriginal Peoples (1996). Report of the Royal Commission on Aboriginal Peoples. Vol. 3: Gathering strength. Ottawa, ON: Canada Communications Group.

Scheffel, D. Z. (2000). The post-anthropological Indian: Canada's new images of Aboriginality in the age of repossession. Anthropologica, 42(2), 175-187.

Silver, J., Mallett, K., Greene, J., \& Simard, F. (2002). Aboriginal education in Winnipeg inner city high schools. Winnipeg, MB: Canadian Centre for Policy Alternatives.

Sockbeson, R. (2011). Cipenuk red hope: Weaving policy toward decolonization \& beyond. Unpublished doctoral dissertation, University of Alberta, Edmonton, AB, Canada. Available at https://era.library.ualberta.ca/items/ec88b0fc-0fa7-40ae-9fcf-4a6bbdfb1deb

South, S. J., Baumer, E. P., \& Lutz, A. (2003). Interpreting community effects on youth educational attainment. Youth and Society, 35(1), 3-36. https://dx.doi.org/10.1177/0044118X03254560

Spring, J. (1998). American education ( $8^{\text {th }}$ ed.). New York, NY: McGraw-Hill.

Steinhauer, E. L. (2007). Parental school choice in First Nations communities: Is there really a choice? Doctoral dissertation, University of Alberta, Edmonton, AB, Canada. Available at http://proquest.umi.com/pqdweb?did=1425301821\&Fmt=7\&clientId=12301\&RQT $=309 \& \mathrm{VName}=\mathrm{PQD}$

Steinhauer, N. R. (1999). "Sohkastwawak": They are resilient (First Nations students and achievement). Master's thesis, University of Alberta, Edmonton, AB, Canada. Retrieved from http://www.collectionscanada.gc.ca/obj/s4/f2/dsk1/tape7/PQDD_0018/MQ47146.pdf

Steinhauer, P. J. (1999). Ininisiwin ekasis'pohtahk watichkwanihk ohci (The inherent wisdom carries on from the roots). Master's thesis, University of Alberta, Edmonton, AB, Canada. Retrieved from http://www.collectionscanada.gc.ca/obj/s4/f2/dsk1/tape7/PQDD_0019/MQ47147.pdf

Stewart, J. (2003). The mommy track: The consequences of gender ideology and aspirations on age at first motherhood. Journal of Sociology and Social Welfare, 30(2), 3-30.

St. Denis, V., \& Hampton, E. (2002). Literature review on racism and the effects on Aboriginal education [Prepared for Minister's National Working Group on Education]. Ottawa, ON: Indian and Northern Affairs Canada.

St. Denis, V. (2007). Aboriginal education and anti-racist education: Building alliances across cultural and racial identity. Canadian Journal of Education, 30(4), 1068-1092. https://dx.doi.org/10.2307/20466679 
St. Denis, V. (2010). A study of Aboriginal teachers' professional knowledge and experience in Canadian public schools. Ottawa: Canadian Teachers' Federation / Canadian Council on Learning.

van der Woerd, K. A., \& Cox, D. N. (2003). Educational status and its association with risk and protective factors for First Nation youth. Canadian Journal of Native Education, 27(2), 208-222.

Véronneau, M., Vitaro, F., Pedersen, S., \& Tremblay, R. (2008). Do peers contribute to the likelihood of secondary school graduation among disadvantaged boys? Journal of Educational Psychology, 100(2), 429-442. https://dx.doi.org/10.1037/00220663.100.2.429

Ward, C. (1995). American Indian high school completion in rural southeastern Montana. Rural Sociology, 60(3), 416-434. https://dx.doi.org/10.1111/j.1549-0831.1995.tb00581.x

Weber-Pillwax, C. (2001). What is indigenous research? Canadian Journal of Native Education, 25(2), 166-176.

Weisfeld, G. E., \& Woodward, L. (2004). Current evolutionary perspectives on adolescent romantic relations and sexuality. Journal of the American Academy of Child \& Adolescent Psychiatry, 43, 11-19. https://dx.doi.org/10.1097/00004583-20040100000010

Wentzel, K. R. (2003). Sociometric status and adjustment in middle school: A longitudinal study. The Journal of Early Adolescence, 23(1), 5-28. https://dx.doi.org/10.1177/0272431602239128

Wigfield, A., \& Wagner, A. L. (2005). Competence, motivation and identity development during adolescence. In A. J. Elliot, \& C. S. Dweck (Eds.), Handbook of competence and motivation (pp. 222-239). New York: Guilford.

Wilson, S. (2008). Research is ceremony: Indigenous research methods. Black Point, NS: Fernwood. 